
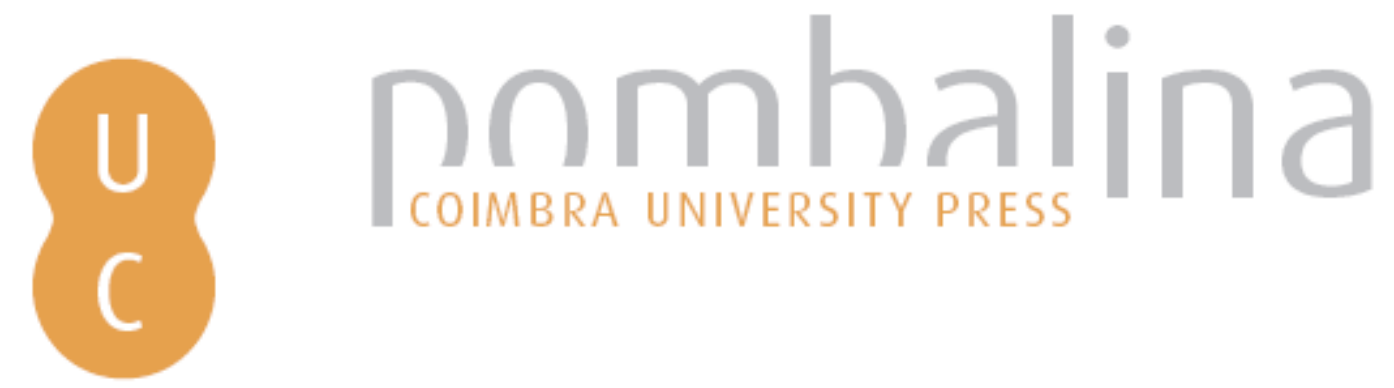

\title{
Práticas, inscrições e redes sociotécnicas: contribuições de Bruno Latour e dos estudos sociais da ciência e da tecnologia para a ciência da Informação
}

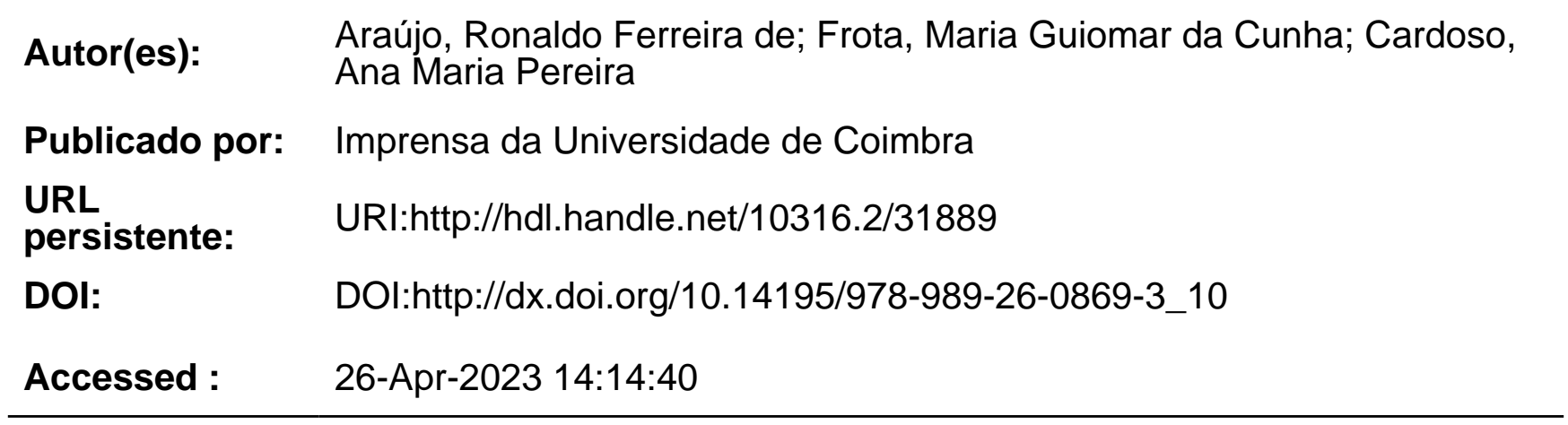

A navegação consulta e descarregamento dos títulos inseridos nas Bibliotecas Digitais UC Digitalis, UC Pombalina e UC Impactum, pressupõem a aceitação plena e sem reservas dos Termos e Condições de Uso destas Bibliotecas Digitais, disponíveis em https://digitalis.uc.pt/pt-pt/termos.

Conforme exposto nos referidos Termos e Condições de Uso, o descarregamento de títulos de acesso restrito requer uma licença válida de autorização devendo o utilizador aceder ao(s) documento(s) a partir de um endereço de IP da instituição detentora da supramencionada licença.

Ao utilizador é apenas permitido o descarregamento para uso pessoal, pelo que o emprego do(s) título(s) descarregado(s) para outro fim, designadamente comercial, carece de autorização do respetivo autor ou editor da obra.

Na medida em que todas as obras da UC Digitalis se encontram protegidas pelo Código do Direito de Autor e Direitos Conexos e demais legislação aplicável, toda a cópia, parcial ou total, deste documento, nos casos em que é legalmente admitida, deverá conter ou fazer-se acompanhar por este aviso.

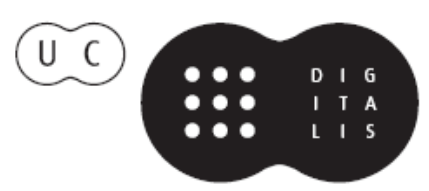


Maria Manuel Borges

Elias Sanz Casado

Coordenação

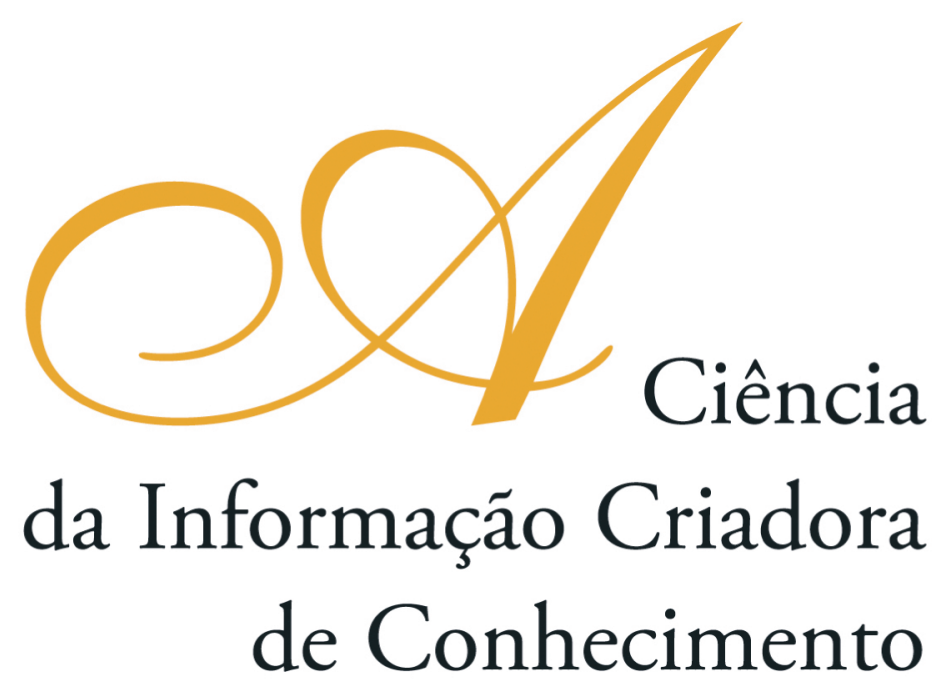

Vol. I I

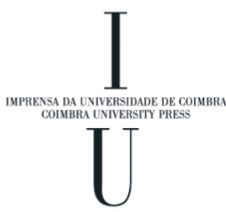

- COImbra 2009 


\title{
Práticas, inscriçốes e redes sociotécnicas: contribuiçốes de Bruno La- tour e dos Estudos Sociais da Ciência e da Tecnologia para a Ciência da INFORMAÇÃo
}

\author{
Ronaldo Ferreira de Araújo \\ Universidade Federal de Alagoas (Brasil) \\ Maria Guiomar da Cunha Frota \\ Universidade Federal de Minas Geral (Brasil)
}

Ana Maria Pereira Cardoso

Pontifícia Universidade Católica (Brasil)

\section{Resumo}

O artigo explora as potenciais contribuições do filósofo francês Bruno Latour para a Ciência da Informaçáo, enfatizando os seguintes temas: a teoria ator-rede, os estudos sociais do conhecimento científico, os estudos de laboratório e a concepção de uma configuração "nãomoderna" da ciência. Considera-se que a aproximaçáo da Ciência da Informação aos Estudos Sociais da Ciência e da Tecnologia pode contribuir significativamente para a consolidaçáo e o empoderamento dos estudos da informaçáo sob uma perspectiva sociocultural.

\begin{abstract}
This paper explores the potential contributions of the French philosopher Bruno Latour for Information Science, and emphasizes the contributions of the actor-network theory, the social studies of scientific knowledge, the laboratory studies and design of a setting "non-modern" in science to Information Science. It is indicated that the approach of Science and Technology Studies can strengthen the sociocultural perspective for information studies.
\end{abstract}

\section{Consideraçóes iniciais}

A grande contribuiçáo da sociologia da ciência, que se organizou sob influência de Robert Merton, foi mostrar a coesáo e a particularidade da estrutura social da ciência, mantidas pela idealização filosófica e por uma salvaguarda comportamental, de natureza social, igualmente idealizada. Mas ambas operando sem questionamentos, garantindo o funcionamento não problemático da ciência.

Até entáo, o conteúdo da atividade científica ainda não era estudado. Com Thomas Kuhn (1992) em A estrutura das revoluçóes científicas, os sociológos encontram respaldo para submeter o conteúdo da ciência ao escrutínio da sociologia abrindo contraposiçóes aos métodos universais e à neutralidade atribuídos à ciência. 
Ao entrar em cena para estudar o conteúdo da ciência, a sociologia da ciência, mantém-se ainda arraigada a uma concepção mais normativa na qual importava o contexto da justificativa na construção dos fatos científicos e desconsiderava-se em sua análise a participação dos artefatos, atores importantíssimos na atividade de pesquisa.

A "nova sociologia da ciência" desenvolvida por Bruno Latour, Michel Callon, John Law e outros retoma e posiciona-se frente a esses aspectos. Opóe-se ao contexto da justificativa e privilegia o contexto de descoberta uma vez que este define a natureza da racionalidade científica, sua objetividade, ou seja, a prova e a verdade; e inclui na análise sociológica da atividade científica, além dos atores sociais (pessoas e grupos), os artefatos, denominados atores não-humanos.

A investigação da descoberta não é mais vista como um fato estabelecido por cientistas, mas como resultado de um processo social que passa a ocupar lugar central nas interpretaçôes da construção dos fatos científicos. Assim, a ciência é entendida como uma construção social, o que não significa que ela seja "irracional”, e sim que sua produção e resultados estâo inseridos na estrutura social como as demais açôes humanas, portanto sujeita aos interesses, conflitos e contradiçóes comuns a qualquer atividade social.

Os atores não-humanos podem ser vistos nas matérias com as quais os pesquisadores se associam no curso de seus projetos de investigação - máquinas, procedimentos de experimentação, bacilos, reagentes, vírus, entre tantos outros meios. São esses nãohumanos que fornecem os dados em inscriçóes (pedaços de papel repletos de números, curvas, modelos, que saem, por exemplo, de um espectrômetro de massa) em nome dos quais os pesquisadores definem fatos verdadeiros e artefatos eficientes e lucrativos.

Os Estudos Sociais da Ciência e da Tecnologia (Science and Technology Studies - STS), ou mesmo, Estudos em Ciência, Tecnologia e Sociedade, que abarcam tais aspectos, apresentam uma perspectiva de investigação que permite uma análise microssocial da ciência. Assim, pode-se pensar o papel dos atores envolvidos nos processos da atividade científica, como eles se articulam na rede sociotécnica que formam, como agenciam outros atores. Trata-se de um modelo baseado na teoria ator-rede (Actor Network Theory - ANT) que considera a prática científica em rede e busca maior compreensão da complexidade dessa atividade seguindo seus atores (cientistas e engenheiros) em seus contextos de produção (Latour, 2000a).

O presente artigo discute brevemente algumas implicações dessa perspectiva para o campo da Ciência da informação, aproximando-o dos STS, segundo a proposta do filósofo francês Bruno Latour, dando ênfase aos aspectos que envolvem a ANT, os estudos sociais do conhecimento científico, os estudos de laboratório e a configuração não-moderna da ciência.

\section{Bruno Latour e os Estudos Sociais da Ciência e da Tecnologia}

Bruno Latour nasceu em Beaune Burgundy, na França. Foi professor do Centre de Sociologie de L'innovation at the Ecole Nationale Supérieure des Mines in Paris (1982-2006) e, atualmente, é professor do Sciences Po Paris e vice-presidente do Centre de Sociologie des Organisations (CSO).

Após ter se formado em filosofia, trabalhou como encarregado de pesquisa na África, desenvolvendo estudos voltados à sociologia do desenvolvimento. A partir de 
então, interessou-se pela antropologia e, mais especificamente pela antropologia das ciências, direcionando seu trabalho no sentido de transpor as categorias antropológicas para a análise da ciência.

A abordagem de Latour está abrigada nos STS que correspondem a uma análise crítica e interdisciplinar da ciência e da tecnologia num contexto social, tendo por objetivo a compreensão dos aspectos gerais do fenômeno científico-tecnológico. Essa linha de estudos volta-se para o conteúdo do saber científico e tecnológico, suas práticas concretas geograficamente situadas, para a natureza de suas inter-relaçóes e sua ligação com o resto do coletivo (Machado \& Teixeira, 2007). Ela apresenta uma perspectiva que entende o conhecimento como náo dualista (Santos, 1987) fundado na superação das distinçóes familiares como sujeito e objeto, observador e observado.

Tal perspectiva rompe com as clássicas polarizaçóes entre natureza e sociedade, contexto de descoberta e contexto da justificaçáo, contexto e conteúdo, centro e periferia, compreendendo os conhecimentos tecno-científicos como efeitos de uma multiplicidade de interações sociais e técnicas (Machado, 2006).

Segundo Benakouche (2005) não devemos entender, como se costuma tradicionalmente pensar, a "ligação" da ciência e tecnologia à sociedade, como pólos apartados que necessitam estabelecer conexóes entre si. Recorrendo a autores no âmbito da sociologia das ciências e das técnicas, ousaríamos afirmar que nossa sociedade se tece com a ciência e a tecnologia, configurando um quadro em que ciência é sociedade, tecnologia é sociedade.

Assertivas assim apóiam-se na opinião de Latour (2001, p.97) de que "a noção de uma ciência isolada de resto da sociedade se tornará táo absurda quanto a idéia de um sistema arterial desconectado do sistema venoso". Para o autor um conceito não se torna científico por estar distanciado do restante daquilo que ele envolve, mas porque se liga cada vez mais estreitamente a um repertório bem maior de recursos, tecendo e atravessando a trama social.

\subsection{A teoria ator-rede}

Teorizada por Michel Serres e operacionalizada por Latour, Callon e Law a teoria ator-rede (ANT) tem sido muito utilizada para correlacionar ciência, tecnologia e sociedade. Ela possui uma forma original de submeter o conteúdo da ciência ao exame minucioso da sociologia trabalhando sempre com a ciência em processo de construção, ou em açáo. Essa ciência em ação (Latour, 2000a) opera em rede e permite remover todo e qualquer centro (detentor da verdade das coisas), não conferindo privilégios a um nó da rede em relação a outro.

Para Law (1992) a noção de rede (de atores ou sociotécnica) é apenas uma maneira de sugerir que a sociedade, as organizaçôes, os agentes e as máquinas são todos produzidos interconectados por certos padrôes e por materiais diversos (humanos e não-humanos). Na ANT a noção de rede está ligada a fluxos, circulações, alianças, movimentos. Conforme a teoria, uma rede de atores não é redutível a um único ator nem a uma só rede; ela é composta de séries heterogêneas de elementos animados e inanimados, conectados e agenciados. 
Ator ou actante pode ser definido por qualquer entidade, elemento, coisa, pessoa, ou instituiçáa que age sobre o mundo e sobre si, sendo capaz de ser representada. Segundo Callon (1998), a concepçáo de ator empregada na ANT se distingue da usada na sociologia tradicional, porque geralmente desconsidera em suas análises o elemento não-humano.

Para que os atores (humanos e não-humanos) sejam mobilizados na rede, é necessário que sejam "traduzidos", o que deve ser entendido não como uma simples mudança de um vocabulário para outro, mas, conforme apontado por Moraes (2004), como um deslocamento, um desvio de rota, uma mediaçáo ou invenção de uma relaçáo antes inexistente, e que de algum modo modifica os atores nela envolvidos, fazendo com que a noção de tradução extrapole a idéia de uma mera interação.

A noçáo de traduçáo deve expressar a simetria entre os pólos sujeito e objeto, sociedade e natureza, e outros, se dizendo em último caso das negociaçōes que envolvem um universo dilatado de elementos e questôes. Para tal traduçáo, de acordo com Teixeira (2001), cabe-nos, a cada estudo, a tarefa de procurar esses elementos, seus elos, as aproximaçōes, as ligaçôes transversais e as rupturas próprias a cada local. Cabe-nos também pensar em seus limites frente ao nosso próprio universo de relaçôes. A ANT entende o sujeito e o objeto do conhecimento como entidades que se definem em relação no meio em que se encontram para produzir suas açôes. Tanto o sujeito define o objeto como o objeto define o sujeito.

A teoria é considerada por alguns autores (Van House, 2004; Moraes, 2004; Machado, 2006; Machado \& Teixeira, 2007) a abordagem analítica mais produtiva dentro dos STS. Embora tenha em sua denominação a palavra teoria inserida por seus idealizadores, o próprio Latour (1999) afirma que ela corresponde mais a um método que, por sua vez, está presente nas principais obras ${ }^{1}$ deste autor utilizadas pela Ciência da Informação no Brasil (Araújo, 2009a).

Ressalta-se que, de acordo com Pereira (2000), a Pós-Graduação em Ciência da Informação (PPGCI) do convênio CNPq/IBICT-UFRJ/ECO foi pioneira no ensino e pesquisa da ANT e das proposiçóes de Latour, Callon, e Law no Brasil ao criar em 1995 um grupo de estudo para ampliar o entendimento da vasta bibliografia produzida por estes autores. Frutos deste pioneirismo foram as teses e dissertaçóes ${ }^{2}$ defendidas no âmbito do programa, que foram analisadas por Araújo e Cardoso (2007). Os autores identificaram a presença de Bruno Latour e da ANT como aporte teórico ou metodológico nos trabalhos e sugerem desdobramentos em novos estudos que busquem perceber a influência deste autor no campo da CI pelas múltiplas possibilidades de análise que ele oferece.

\footnotetext{
${ }^{1}$ Ciência em ação (2000), Redes que a razão desconhece (2000), Jamais fomos modernos (1994) e Vida de laboratório (1997). A constataçâo de serem estas as principais obras do autor presentes no campo da ciência da informação foi feita por meio de um estudo de citaçôes no qual foram analisadas na produção científica da ciência da informaçấo no Brasil artigos de periódicos (43) que tiveram Bruno Latour como referência. Além das obras o trabalho apresenta quais são os pesquisadores da ciência da informação no Brasil que mais citam Bruno Latour e aspectos dos STS.

${ }^{2}$ Os autores por meio da análise de conteúdo verificaram 14 trabalhos entre teses (3) e dissertaçóes (11) em ciência da informação no período de 1996 a 2000 que tiverem a ANT e Bruno Latour como referencial teórico-o-metodológico.
} 


\subsection{Os estudos sociais do conhecimento científico}

Bruno Latour e outros integrantes dos STS, adeptos da ANT em suas discussões, apontam que o conhecimento é um produto social, mais do que algo gerado a partir da operação de um método científico privilegiado, e que tal conhecimento (generalizado) pode ser visto como produto ou efeito de uma rede de materiais heterogêneos.

Segundo Law (1992), o conhecimento pode vir expresso em uma variedade de formas materiais. Mas nos deixa a pergunta: de onde ele vem? A resposta advinda da ANT é de que o conhecimento é o produto, o resultado final de uma série de trabalhos complexos em que os fragmentos e partes heterogêneas partem de suas justaposiçóes para a dinâmica híbrida da rede.

Essa postura lhe oferece capacidade para lidar com a proliferação dos híbridos, não só das coisas, do não humano, mas também do humano, pois conforme o autor:

[...] nós mesmos somos híbridos, instalados precariamente no interior das instituiçôes científicas, meio engenheiros, meio filósofos, um terço instruídos sem que o desejássemos; optamos por descrever as tramas onde quer que estas nos levem. Nosso meio de transporte é a noçâo de rede. Mais flexível que a noção de sistema, mais histórica que a de estrutura, mais empírica que a complexidade, a rede é o fio de Ariadne destas histórias confusas. (Latour, 1994. p. 9)

Assim como Latour, Michel Callon (1998), também preconiza o "sermos híbridos", em seu trabalho ${ }^{3}$, onde identifica na ANT a possibilidade do estudo da tecnologia ser transformado em um instrumento para análises sociológicas. O estudo de Callon envolveu engenheiros e após analisá-los, o autor conclui que se trata de engenheirossociólogos ${ }^{4}$, pela prática híbrida da atividade.

Nos STS o conhecimento científico não é resultado da aplicação imparcial de claros critérios técnicos de adequação, mas de fatores tais como os recursos retóricos dos praticantes e suas adesóes socialmente negociadas. Ao aproximar-se das práticas que envolvem a atividade científica e proceder a uma observação cuidadosa de cientistas trabalhando, percebe-se que o conhecimento científico não é uma representação objetiva e imparcial de um mundo natural independente, mas, pelo contrário, uma criação ativa e comprometida desse mundo no transcorrer da interação social.

Assim as conclusóes da ciência são formulaçôes socialmente contingentes que foram consideradas adequadas por grupos específicos em determinadas situaçóes culturais e sociais. Segundo Latour para que possamos compreender e explicar o fenômeno científico há que se estabelecer um nexo real entre o conteúdo científico e o contexto social. E a descrição da produção social desse conhecimento é objetivo da sociologia da ciência, sendo agora uma "sociologia dos saberes", superposta e misturada a uma epistemologia (Latour \& Woolgar, 1997, p. 20).

\footnotetext{
${ }^{3} \mathrm{O}$ autor propõe uma nova interpretação da dinâmica tecnológica. Ilustra a capacidade dos engenheiros em atuar como sociólogos (historiadores e economistas) ao descrever os aspectos observados no desenvolvimento de uma inovação, a introdução do veículo elétrico (VEL) na França.

${ }^{4}$ Termo traduzido do original: ingenieros-sociólogos (p.143) da obra: DOMÉNECH, Miguel; TIRADO, Francisco J. Sociologia simétrica. Barcelona: Gedisa, 1998.
} 
A construção social do conhecimento na perspectiva dos STS teria implicaçóes diretas sobre algumas questôes epistemológicas da ciência da informação, seja para lidar com os conflitos e interesses (próprios dos sujeitos do conhecimento) presentes na atividade científica do campo, seja na importância do papel do documento e da informação nas práticas que a área envolve, ou mesmo na possibilidade de refletir sobre os limites do campo no que diz respeito a suas questôes (fronteiras) interdisciplinares no traço entre seu contexto social e conteúdo científico.

\subsection{Estudos de Laboratório}

A obra Vida de laboratório (Latour \& Woolgar, 1997) tem sido considerada um clássico dos chamados estudos sociais da ciência. Ela marca o debate contemporâneo da sociologia da ciência e reforça a centralidade assumida pela abordagem etnográfica, perspectiva metodológica precursora para a análise da ciência proposta no livro.

O estudo etnográfico do laboratório foi, para Latour e Wooglar (1997), uma ocasião para investigar a atividade científica como uma prática social especialmente pertinente ao propósito de gerar informaçóes sobre os processos sociais de raciocínio e argumentação em geral. Assim, o exame das atividades rotineiras de um laboratório, conforme apontam os autores, contribui para a construção social dos fatos, evidenciando o caráter peculiar, local, heterogêneo e contextual das práticas científicas. Seguindo uma vertente oposta ao pensamento dualista, Latour propóe em uma abordagem pragmática que não privilegia só o técnico ou só o social, mas é capaz de respeitar a dinâmica não hierárquica e não linear de suas relaçôes, negando, assim, a própria separação entre o "lado de dentro" e o "lado de fora" do laboratório.

$\mathrm{O}$ argumento central proposto no livro é que, diferente do preconizado pela epistemologia, a ciência não se diferencia de outras práticas sociais em função de uma superioridade cognitiva derivada da racionalidade intrínseca a essa atividade. Sendo assim, o cientista é visto como qualquer outro ator social, isto é, como alguém que se utiliza de estratégias persuasivas que visam garantir a aceitação dos enunciados por ele produzidos. A perspectiva de Latour e Wooglar (1997) é a da simetria, ou seja, a ideia de que tanto o enunciado científico «verdadeiro» quanto o "falso» assumem tais atributos não por suas qualidades internas distinguidas pelo «bom» ou «mal» uso do método científico, mas em função de um processo social de convencimento que possibilitou serem reconhecidos enquanto tais.

Trabalhando com a noção de inscriçôes, Latour e Wooglar (1997) referem-se aos procedimentos de materialização dos objetos de estudo da ciência através de traços, pontos, gráficos, espectros e demais registros produzidos por aparelhos manipulados no sentido de formalizar literariamente os fenômenos que servirão posteriormente de matéria-prima para a elaboração dos enunciados científicos.

Os cientistas elaboram seus enunciados a partir das inscriçóes. Os enunciados, por sua vez, são de diferentes tipos e, através de um conjunto de operaçóes sobre (e entre) eles, os cientistas buscam transformar os que se apresentam como assertivas meramente especulativas em enunciados referentes a um fato plenamente instituído.

Um enunciado, todavia, não existe por si só, mas sim nos contextos contingentes e específicos em cada momento de configuração desse campo de forças. No caso de mudança 
nas condiçôes do contexto local, mudam necessariamente as operaçôes entre enunciados postas em prática e, consequentemente, os rumos do processo de construção do fato.

Os autores destacam a característica peculiar que distingue o processo de transformação de um enunciado em um fato estabelecido. Tal processo se realiza na medida em que lança mão de dispositivos pelos quais se torna muito difícil detectar qualquer traço de sua produção. Assim, um fato científico é reconhecido quando perde todos seus atributos temporais e integra-se ao conjunto de conhecimentos edificados por outros fatos, alcançando uma qualidade que lhe permite eliminar as referências ao contexto social e histórico a partir do qual foi construído e, consequentemente, resistir às tentativas de explicá-lo sociológica e historicamente.

O argumento dos autores é que a construção do fato científico envolve, essencialmente, uma delicada negociação entre os cientistas, que, para isso, se valem de múltiplas estratégias que lhes garantem o crédito como recompensa. No processo de negociação, o reinvestimento contínuo dos recursos acumulados forma o ciclo de credibilidade. O traço marcante desse ciclo é a "busca contínua por um ganho de credibilidade permite o reinvestimento e, por conseguinte, um ganho posterior de credibilidade" (Kropf \& Ferreira, 1998, p. 594).

A abordagem de cunho etnográfico aplicada ao estudo desenvolvido no livro deixa uma questão fundamental a ser considerada, a qual diz respeito ao seu valor metodológico enquanto chave para especificar o caráter da atividade científica e tem por base a "cláusula» da observação da ciência "como ela acontece". Assim a descrição etnográfica da cadeia de eventos e práticas que dão forma concreta a sua interação é a contribuição mais original dos autores.

Do ponto de vista metodológico, Latour afirma que a única maneira de compreender a realidade dos estudos científicos é seguir os cientistas em ação, já que a ciência está fundada sobre uma prática, e não sobre ideias. Para isso, é preciso prestar atenção aos detalhes da prática científica, descrevendo essa prática tal como os antropólogos descrevem tribos selvagens. Trata-se de uma antropologia da ciência.

Implicações desta postura para a ciência da informação podem ser visualizadas no aspecto prático e material atribuído à informação (Latour, 2000b) e a ênfase que os estudos de laboratório dão ao registro, às práticas, às ferramentas e às técnicas na construção do conhecimento, com atenção especial à interação entre seus atores (humanos e não humanos).

\subsection{A configuração "não-moderna"}

Em Jamais fomos modernos Latour (1994) concentra-se em problematizar a ideia da existência de uma rígida separaçáo entre natureza e sociedade, tecnologia e sociedade, da dicotomia entre sujeito e objeto e ainda de uma relação de domínio dos homens sobre as coisas do mundo; ideias ditadas pela modernidade, que na realidade, segundo o autor, são ideias que nunca vingaram.

Para sustentar a ideia central da obra, ou mesmo a hipótese radical "de jamais termos sidos modernos", Latour parte de uma investigação da "constituição" moderna (o que esta permite e proíbe), resgata a construçáo ideológica que a fundamenta, e traça um paralelo entre a sociedade dos modernos e dos "não modernos". 
Moderno, modernização e modernidade, segundo Latour (1994, p.15) são palavras que quando aparecem, definem, por contraste, "um passado arcaico e estável". Além disso, essas palavras encontram-se sempre colocadas em meio a uma polêmica, "em uma briga onde há ganhadores e perdedores, os Antigos e os Modernos". Assim, moderno, portanto, "é duas vezes assimétrico: assinala uma ruptura na passagem regular do tempo; assinala um combate no qual há vencedores e vencidos".

Mas Bruno Latour (1994, p.16) não define modernidade como uma época e sim uma atitude que envolve dois conjuntos de práticas distintas: o de tradução e o de purificação. A primeira "cria misturas entre gêneros de seres completamente novos, híbridos de natureza e cultura". A segunda cria "duas zonas ontológicas inteiramente distintas, a dos humanos de um lado, e a dos náo humanos de outro", a dos sujeitos e a dos objetos.

Para o autor, enquanto consideramos separadamente estas práticas, somos realmente modernos, mas a partir do momento em que desviamos nossa atenção simultaneamente para o trabalho de ambos (hibridação e purificação), deixamos instantaneamente de sermos modernos e nosso futuro começa a mudar. Ao proibir o "pensar os híbridos" obteve-se o aumento de sua proliferaçáo, este é o paradoxo dos modernos.

Lidar com a proliferação dos híbridos não é uma tarefa trivial, principalmente na realidade científica moderna. Latour (1994, p.11) chega a dizer que "nossa vida intelectual é decididamente mal construida". O autor faz tal afirmaçáo ressaltando a dificuldade (apresentada pela ciência moderna) de transpor, de transdisciplinar, de sair da fragmentação, de perceber-se em rede. Ilustra essa dificuldade dizendo que " $a$ epistemologia, as ciências sociais, as ciências do texto, todas têm uma reputaçáo conquanto que permaneçam distintas. Caso os seres que você esteja seguindo atravessem as três, ninguém mais compreende o que você diz".

Assim se oferecermos uma bela rede sociotécnica a essas três disciplinas estabelecidas: a epistemologia extrairá os conceitos e arrancará deles todas as raízes que poderiam ligá-los ao social ou à retórica; as ciências sociais "amputarão a dimensáo social e política, purificando-a de qualquer objeto", e; as ciências do texto "conservarão o discurso, mas irão purgá-lo de qualquer aderência indevida à realidade e aos jogos de poder".

A ciência da informação tem sido considerada como oriunda da pós-modernidade (Wersig, 1993; Cardoso, 1996; Araújo, 2003; Francelin, 2004), na qual a condição de pós-moderno é expressa como legítima condição representativa da atualidade. Nesse sentido, desvinculada do passado (moderno), o campo surge dentro de um novo paradigma científico (Renault, 2007): uma nova disciplina ou uma nova ciência (Wersig, 1993; Araújo, 2003; Renault, 2007) que, de tấo imbricada na pós-modernidade, é quase que impossibilitada de promover o debate sobre seu estatuto científico fora desse contexto (Francelin, 2004).

Se assim for e restar à CI somente esse lugar para debater seu estatuto científico, cabe ao menos ressaltar que o discurso pós-moderno e as teorias que o compóem não expressam um corpo conceitual coerente e unificado (Moraes, 1996) e que a ideologia pós-moderna é o principal subproduto da ideologia do novo regime de acumulação do capital (Chauí, 2001) que reforça a hegemonia pelo pensamento neoliberal (Pina, 2008), sendo esse o mesmo movimento realizado pela chamada sociedade da informação (Bemfica, Cardoso \& Faria, 2003).

Bruno Latour náo aceita os pressupostos do discurso construtivista pós-moderno afirmando ser esse um discurso vazio, significando apenas um sintoma da crise e não um 
programa consistente. Ao refletir-se sobre a configuração epistemológica do campo da ciência da informação, fica o desafio de assumir as contradiçôes da própria modernidade no pensamento científico, seguir o percurso de uma nova antropologia como o lugar da reflexão sobre a ciência, ultrapassando os limites da sociologia do conhecimento e, sobretudo, da própria epistemologia. Essa antropologia pretende romper com as cisóes natureza/sociedade, global/local e outras assimetrias propostas pela modernidade, entre elas a separação radical entre as verdadeiras ciências e as falsas.

\section{Consideraçôes finais}

Práticas bem localizadas, inscriçôes que registram relaçôes, negociaçôes e acordos nas redes sociotécnicas que se formam na atividade científica são percebidos nos STS. O embasamento teórico-metodológico da ANT, a perspectiva da produção social do conhecimento e os estudos de laboratório permitem uma visão interna e externa da produção dos fatos e artefatos da tecnociência (Latour 2000a).

Como recurso metodológico a ANT permite um detalhamento tanto o aspecto coletivo da construção e da transferência do conhecimento quanto o seu processo de estabilização. O arcabouço teórico da ANT permite identificar e seguir os atores, as redes, os agenciamentos e os movimentos nas articulaçôes que envolvem a produção, circulação e uso de informaçóes registradas e documentos. Vale ainda lembrar que a noção de regime de informação de Frohmann (1995) foi desenvolvida a partir das implicações teóricas da ANT.

O cunho etnográfico dos estudos de laboratório permite uma análise do cotidiano da atividade científica, das práticas diárias, dos ritos, dos ciclos de credibilidade, dos conflitos, da motivação, dentre outros. Evidenciam-se questôes microssociais do fazer científico, dando ênfase ao aspecto material da informação, seu registro e circulação necessários à produção e transferência do conhecimento científico.

Aproximar os STS da ciência da informação, na possibilidade de uma nova perspectiva de investigação para o campo, pode contribuir significativamente para a consolidação e o empoderamento dos estudos da informação sob uma perspectiva sociocultural, rompendo com a visão distanciada e global da ciência, para achegar-se aos espaços de produção das pesquisas - institucional, social, e culturalmente - localizados.

No Brasil, além do já mencionado pioneirismo do PPGCI do convênio CNPq/ IBICT-UFRJ/ECO no ensino e pesquisa da ANT e das proposiçóes de Latour (Pereira, 2000), por meio de teses, dissertaçóes e artigos de periódicos da área (Araújo e Cardoso (2007); Araújo (2009a, b) percebe-se, um movimento de aproximação da ciência da informação aos STS. Podem ser identificados grupos de pesquisa ${ }^{5}$ e até mesmo de uma

\footnotetext{
5 Grupos: “INFOCIÊNCIA História, Epistemologia e Política da Informação Científica”, ligado ao Programa de Pós-Graduação em Ciência da Informação da Universidade Federal da Bahia - UFBA; "Grupo de estudos e trabalhos em informática e sociedade", ligado ao Instituito de Informática da Pontifícia Universidade Católica de Minas Gerais - PUC Minas; "Ciência, Tecnologia e Sociedade" do Departamento de Ciência da Informação da Universidade Federal de São Carlos - UFSCar; "Informação, Tecnologia e Sociedade", ligado ao Departamento de Ciência da Informação da Universidade Federal de Santa Catarina - UFSC. Esses e outros grupos de pesquisa que estudam perspectivas STS para a ciência da
} 
"Revista em Ciência, Tecnologia e Sociedade" ligada ao Departamento de Ciência da Informação e ao Programa de Pós-Graduação em Ciência, Tecnologia e Sociedade da Universidade Federal de São Carlos que aguarda a publicaçáo de sua primeira edição. Considera-se como algo positivo para a ciência da informação esses movimentos que tendem a garantir espaços de debates, reflexôes e uma agenda de pesquisa e investigação em torno das potenciais contribuiçóes da vertente STS para o campo.

\section{Referências bibliográficas}

Araújo, C. A. A. (2003). Ciência da informação como ciência social. Ciência da Informação, Brasília, v. 32, n.3, 21-27. Disponível em: http://revista.ibict.br/

Araújo, R. F. (2009a). Apropriaçōes de Bruno Latour pela ciência da informação no Brasil: descrição, explicação e interpretação. (139). Dissertação (Mestrado em Ciência da Informação) - Escola de Ciência da Informação, Universidade Federal de Minas Gerais. Belo Horizonte.

Araújo, R. F. (2009b). Leituras de Bruno Latour na ciência da informação: analisando citações. In: Anais do IX Encontro Nacional de Ensino e Pesquisa em Informação (CINFORM), 9, Salvador, BA: Universidade Federal da Bahia.

Araújo, R. F., \& Cardoso, A. M. P. (2007). A ciência da informação como rede de atores: reflexôes a partir de Bruno Latour. In: Anais do VIII Encontro Nacional de Pesquisa em Ciência da Informação (ENANCIB), 8, 2007, Salvador, BA. Universidade Federal da Bahia.

Bemfica, J., Cardoso, A. M. P. \& Faria, C. A. P. (2003). Sociedade da Informação: estratégia para uma sociedade mercadorizada. Revista Informática Pública, Belo Horizonte, v. 5, n. 2, 185-201.

Benakouche, T. (2005). Tecnologia é sociedade: contra a noçâo de impacto tecnológico. In: Dias, L. C. \& Silveira, R. L. L. (Org.). Redes, sociedades e territórios. 1a. ed. Santa Cruz do Sul: EDUNISC, v. , 79-106.

Callon, M.(1998). El proceso de construcción de la sociedad: el estudio de la tecnología como herramienta para el análisis sociológico. In: DOMÉNECH, M. \& TIRADO, F. J. (Eds.) Sociologia simétrica. Barcelona: Gedisa, 143-170.

Cardoso, A. M. P. (1996) Pós-Modernidade e informação: conceitos complementares? Perspectivas em Ciência da Informação, Belo Horizonte, v. 1, n. 1, 63-79. Disponível em: http://www. eci.ufmg.br/pcionline

Chauí, M. (2001) Escritos sobre a Universidade. São Paulo: Editora UNESP.

Francelin, M. M. (2003) A epistemologia da complexidade e a Ciência da Informação. Ciência da Informação, Brasília, v. 32, n. 2, 64-68. Disponível em: http://revista.ibict.br/

Frohmann, B. (1995). Taking information policy beyond information science: applying the actor network theory. In H. A. Olson \& D. B. Ward (Eds.), Connectedness: Information, systems, people, organizations (19-95). Edmonton, Alberta: School of Library and Information Studies, University of Alberta.

Latour, B. (1999). On recalling ANT. In J. Law \& J. Hassard (Eds.), Actor network theory and after. (15-25). Oxford: UK Blackwell.

informação podem ser consultados no Diretório dos Grupos de Pesquisa (DGP) do Conselho Nacional de Desenvolvimento Científico e Tecnológico (CNPq), disponível no: http://dgp.cnpq.br 
Latour, B. (2000a). Ciência em ação: como seguir cientistas e engenheiros sociedade afora. Sáo Paulo: UNESP.

Latour, B. (2000b). Redes que a razão desconhece : laboratórios, bibliotecas, coleções. In: Baratin, M. \& Jacob, C. (coord.) O poder das bibliotecas : a memória dos livros no ocidente. (21-44), Rio de Janeiro: UFRJ.

Latour, B. (2001). A Esperança de Pandora: ensaios sobre a realidade dos estudos científicos. São Paulo: EDUSC.

Latour, B. (1994). Jamais fomos modernos: ensaio de antropologia simétrica. Rio de Janeiro: Ed. 34.

Latour, B. \& Woolgar, S. (1997). A vida de laboratório : a produção dos fatos científicos. Rio de Janeiro: Relume Dumara.

LAW, J. (1992). Notes on the Theory of the Actor-Network: Ordering, Strategy and Heterogeneity. Systems Practice v.5, n.4, 379-393. Disponível em: http://www.lancs.ac.uk/fss/sociology

Machado, C. J. S. (2006). A invenção científica segundo o modelo da sociologia dos cientistas e os Social Studies of Science. Ciência e Cultura, São Paulo, v.58, n.3, 4-5.

Machado, C. J. S. \& Teixeira, M. O. (2007). Descoberta, invenção e inovação segundo os Estudos Sociais Anglo-saxões e Europeus das Ciências. Datagramazero - Revista de Ciência da informação, Rio de Janeiro, v. 8, 1-37. Disponível em: http://www.dgz.org.br

Moraes, M. A. (2004). Ciência como rede de atores: ressonâncias filosóficas. História, Ciências, Saúde - Manguinhos. Rio de Janeiro, v. 11, n.2, 321-333. Disponível em: http://www. scielo.br

Moraes, M. C. M. Os «Pós-ismos» e outras querelas ideológicas. Perspectiva, Florianópolis, NUP/CED: Editora da UFSC, v. 14, n. 25. Disponível em: http://www.periodicos.ufsc. br/index.php/perspectiva/article/view/10578/10112

Pereira, M. N. F. (1995). A ciência da informação e a nova sociologia da ciência. Informare: Cadernos do Programa de Pós-graduação em Ciência da Informação, Rio de Janeiro , v.6, n.1 , 5-11.

Pina, L. D. (2008). Crítica ao discurso pós-moderno sobre diferença. In: Anais do VI Seminário do Trabalho: trabalho, economia e educação, Marília: UNESP.

Renault, L. V. (2007). A Ciência da Informaçẫo e sua configuração epistemológica: análise com base nas linhas de pesquisa da área. (165). Dissertação (Mestrado em Ciência da Informação) - Escola de Ciência da Informação, Universidade Federal de Minas Gerais. Belo Horizonte.

Santos, B. S. (1987). Um discurso sobre as ciências. Porto: Afrontamento.

Kropf, S. P.; Ferreira, L. O. (1998). A prática da ciência: uma etnografia no laboratório. História, Ciências, Saúde - Manguinhos, v.3, n.5, 589-597. Disponível em: http://www.scielo.br

Kuhn, T. S. (1992). A estrutura das revoluçóes cientificas. 3.ed. São Paulo: Perspectiva.

Teixeira, M. O. (2001). A ciência em ação: seguindo Bruno Latour. História, ciências, saúde - Manguinhos. Rio de Janeiro, v. 8, n. 1, 265-289. Disponível em: http://www.scielo.br

Van House, N. A. (2004). Science and Technology Studies and Information Studies. Annual Review of Information Science and Technology, Medford, NJ: Information Today, n. 38, 3-86.

Wersig, G. (1993) Information Science: the study of postmodern knowledge usage. Information Processing and Management. v.29, n.2, 229-239. 